\section{fites of (Cager}

\author{
ON iN
}

\section{OUTBREAK OF SYPHILIS FOLLOWING ON \\ TAT TOO I N G. ${ }^{1}$}

By Surgeon F. R. BARKER, M.B.Lond., Medical Staff.

ON October 5th, 1888, Case I was admitted into the Station Hospital, Portsea, and placed under my charge suffering from two ulcers on the flexor surface of his left forearm, said to be due to tattooing; they were treated by me as poisoned wounds, probably due to dirty or rusty needles.

But on October 7th, 1888, Case II and Case IIr were admitted from the same regiment with ulcerated arms following on tattooing, with indurated bases, and slight copper-coloured discoloration of the skin. It at once struck $m \theta$ that they were syphilitic in origin, and on examining them I found that their cervical, brachial, and inguinal glands were enlarged, and that Cases $\mathrm{I}$ and II had a faint roseolar rash over their bodies. I also learnt that they had all been tattooed by the same person, a civilian (a discharged soldier of the regiment), who was a hawker in barracks, and whose name I afterwards learnt to be S. I suspected the cause must rest with this man, and that he had transmitted the virus by his saliva: but on questioning these three cases if the man $S$. had put the needles in his mouth or used his saliva in any form, they stoutly denied it. I at once made inquiries to find the man S., letting it be known that he need not fear any punishment, and that I would make it worth his while to come and see me, but he mysteriously disappeared and no trace of him could be found. The officer commanding was communicated with, who issued an order cautioning the men against being tattooed by the man $S$., and ordering all men who had been tattooed by him to come up for medical inspection.

Case Ir informed me that his brother, a non-commissioned officer in the regiment, had been tattooed at the same time as himself, and that his arm was just commencing to be bad.

On October 9th, 1888, the brother (Case IX) came up for inspection, but was not admitted till October 17th, but his arm, together with Cases I, II, III, and IV, were photographed that day by Surgeon D. Wardrop, M.S., to whom I am indebted for the good plates.

Case IV was different to any previously seen, consisting of three well-marked rupial ulcers at the seat of tattooing, and which became still more marked, which I had taken by Messrs. Symonds and Co.

On October 13th, 1888, Case v was admitted with two wellmarked rupial ulcers, from which the scabs were just falling off.

Case IX informed me that he had seen $S$. mix his colours with his saliva. This made me the more anxious to find the man, and on the afternoon of October 13th, whilst on orderly duty, I was informed that someone wanted to see me, and it turned out to be $S$. I told him there was no blame attached to him for tattooing the men, as he was not aware what mischief he was doing. I asked him how many he had tattooed. He stated that he had done about fifteen, but might have done a few more; that he used ordinary needles, which he might have put in his mouth, but denied that he had ever mixed the colours with his saliva, or applied his saliva to the arms in any way. Whilst he was answering these questions I noticed that his hair was very thin; but, on asking him, he denied that it came out. He denied ever having syphilis, but had had gonorrhœe. I noticed a sore at the angle of his mouth, and drew his attention to it. He said it had been there for some time. I asked him if he minded my examining it. On getting him to open his mouth I found the whole of the buccal mucous membrane covered with mucous tubercles, and the soft and hard palate ulcerated. I asked him if he had not an eruption on his skin, and found the front of the chest covered with psoriasis and lepra. I asked him if he had ever had a chancre on his penis, and, on his denying it, asked him if he minded my seeing

1 Read before the South-Fast Hants District of the Southern Branch. 5 his penis. On showing it, thera was a dark pigmented scar on the glans penis about the size of a shilling." On asking what that was, he said it was something that came a year ago since he left the service, and, being very poor, he had not been able to get any treatment for it. He finally let me examine his arms; where found condylomata. Wishing my brother officers to see him, I asked him to come up on October 15th, and I would give him halfa-crown and some medicine to cure him. He came according to promise, and then owned he had wetted his finger and rubbed it on the wounds. I procured a pass for him into the barracks to pick out the men he nad tattooed, he having only tattooed men of one regiment; nevertheless all the men of the other corps in garrison who had been tattooed within the last three months previous to October were examined, but no case of syphilis was discovered to have followed.

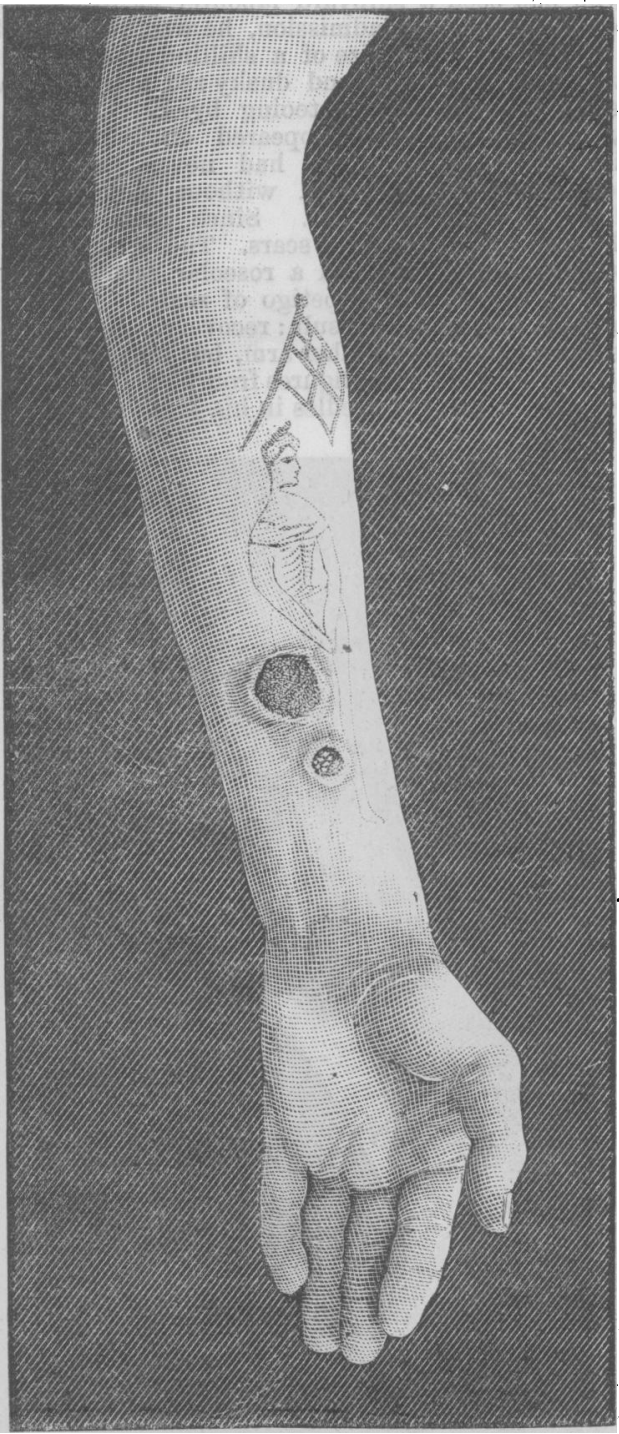

Fig. 1.-Case I.

On October 15th, Case vr was admitted with two scars, which had healed, with copper stains, and well-marked secondary phenomena, as rash, enlarged glands, and condylomata.

On October 16th, Cases VII and VIII were admitted. In each case the ulcers had healed, and well-marked socondary symptoms were developed. In the case of. VIII they assumed a rupial form, and were four in number.

On October 17th, Case.Ix, whose arm had become worse, and [1479] 
the ulcer larger in area, with the true characteristics of a Hunterian chancre, was admitted.

On October 19th, Case $x$ was admitted with two ulcers, from which rupiæ had fallen off, leaving them not quite healed, and the patient having marked secondary phenomena.

On October 23rd, Case XI came to hospital for inspection. $\mathrm{He}$ was found to have scars of three Hunterian chancres of a copper colour, and slight roseolar rash, but was not admitted, but allowed to proceed with his regiment to Malta.

Case XII had proceeded to India to join the first battalion of the regiment before this was discovered, but we learn that he has scars of two rupial sores, and secondary symptoms.

Cases of Syphilis following on Tattooing.

Case I.-Private J. G.; aged 19 ; service 1 year. Admitted on October 5th; discharged on November 11th. A fresh-complexioned youth, who had been a shipyard labourer at Newcastle-on-Tyne prior to enlistment. On admission, he was found to have two circular ulcers about the size of a shilling and sixpence respectively, with ulcerated bases and dusky red margins on front of left forearm following on tattooing by $S$. He was tattooed on July 1st, and the ulcers appeared on September 20th, an incubation of 87 days. He had never had syphilis, and had been proviously tattooed without any ill-result; his brachial glands were enlarged. Since admission, the ulcers healed, leaving copper-coloured scars. The cervical and inguinal glands were enlarged. He had a roseolar rash on his chest and abdomen, sore throat, and impetigu of scalp. Treatment: mercury, pot. iod., and tonics ; result : recovery. He was tattooed by S. at the same time on the other arm, but no ulcers formed. The tattooing consisted of female figures from patterns. He stated that he never saw S. put the needles in his mouth, or use his saliva in any manner.

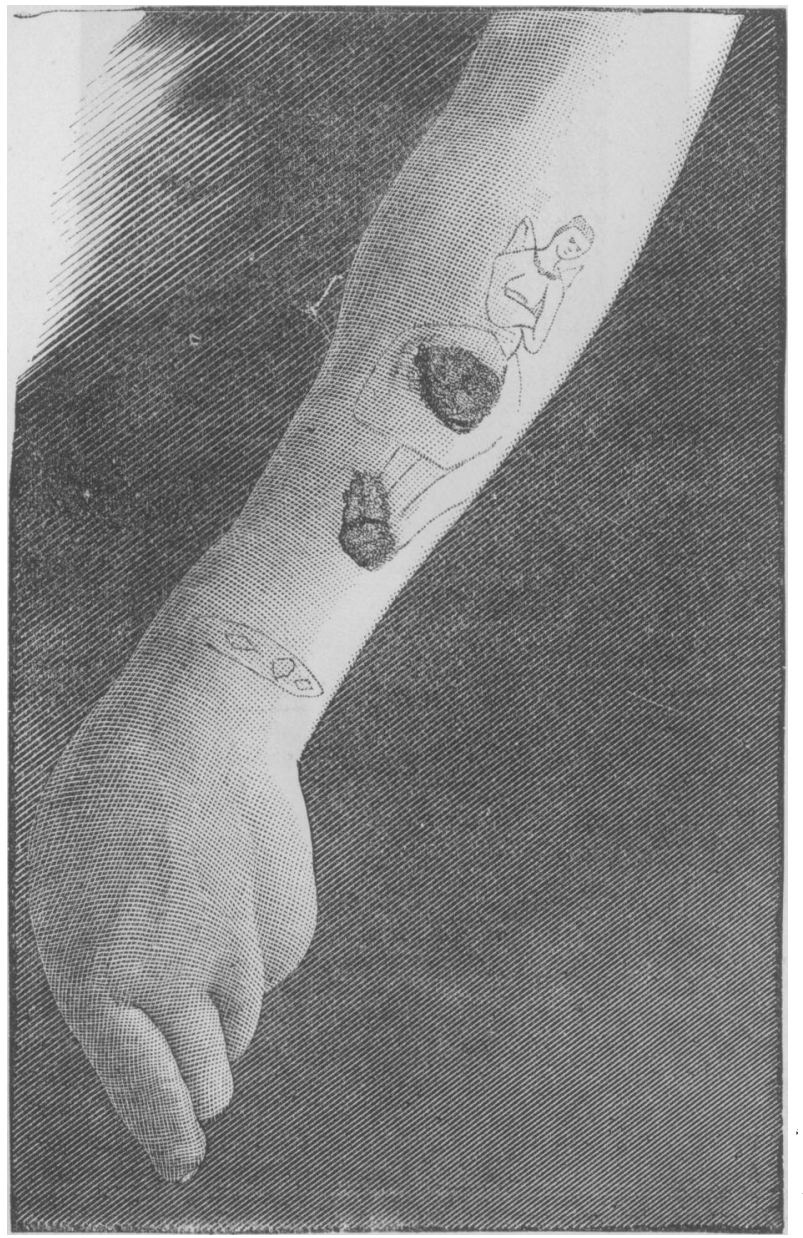

Fig, 2,- Dase II.
CASE II.-Private A. L.; aged 20; service 2 years. Admitted on October 7th, 1888; discharged on December 11th. A freshcomplexioned youth, who had been a zinc-worker in London prior to enlistment. On admission, he was found to have two ulcers with indurated bases and dusky red margins, and punchedout typical Hunterian chancres on the back of his left forearm, the result of tattooing by $S$. He was tattooed on August 5th, and the ulcers appeared on September 2nd, an incubation of 29 days. The brachial glands were found to be enlarged, and there was also a faint roseolar rash on the abdomen. Since admission the ulcers scabbed, and on their falling off two rupiæ formed (November 11th) on their bases. His cervical and inguinal glands were enlarged, and the roseolar rash more marked, with psoriasis guttata and sore throat. He had never had syphilis before. Treatment : mercury, pot. iod., and tonics; result: recovery. He had a bracelet tattooed by $\mathbf{S}$. below the female form from a pattern, which did not ulcerate. $\mathrm{He}$, too, stated that he never noticed $\mathrm{S}$. put the needles in his mouth, or use his saliva in any manner.

CASE III.-Private G. R. S., aged 19 ; service 9 months. Admitted on October 7th, 1888; discharged on November 30th. A fresh-complexioned youth, who drove a horse and cart in London prior to enlistment. On admission he was found to have an ulcer the size of a shilling, with punched-out look, with indurated base and dusky red margins like a Hunterian chancre at the back of the right forearm, the result of tattooing by $S$. The brachial and cervical glands were found enlarged. He was tattooed on August 5 th, and the ulcer appeared on September 20th, an incubation of 47 days. He had never before had syphilis. Since admission the wounds scabbed and healed, and induration disappeared. He had sore throat, enlarged glands, and a roseolar rash over the abdomen and chest. The scar had a copper-coloured staining. Treatment: mercury, pot. iod., and tonics ; result: recovery. He had been previously tattooed, but no ulceration followed. He also stated that he never noticed S. put the needles in his mouth or use his saliva in any manner.

CASE IV.-Private A. M., aged 20 ; service 11 months. Admitted on October 9th, 1888; discharged on November 30th. A freshcomplexioned youth, who was a pianoforte maker in London prior to enlistment. On admission he was found to have three wellmarked rupial ulcers, with indurated bases and dusky red margins. The rupiæ were very perfect, like limpet-shells. The ulcers were situated over the site of a flower and flower-pot tattooed by $S$. on the flexor surface of his left forearm. His cervical and brachial glands were enlarged. He was tattooed on August 11th, 1888, and the ulcers appeared on the 23rd of the same month, an incubation of 13 days. Owing to the short incubation period I tried all I could to make the patient gainsay himself, but he stoutly affirmed that that was the correct time. He had never had syphilis before. Since admission, the rupial ulcers (scabs) fell off, leaving plain-surfaced scars of a copper colour. He had lepra on his forehead, sore throat, condylomata, roseolar rash over the abdomen, and psoriasis. His inguinal glands also became enlarged. He had been previously tattooed, but not by S., on the opposite arm, but no ulceration followed. Treatment: mercury, pot. iod., and tonics; result : recovery. He stated that $S$. did not use his saliva in any form or put the needles in his mouth, but the needles looked as if they had been used before and the ink had dried on them.

CASR V.-Private J. T., aged 19 ; service 10 months. Admitted on October 13th, 1888; discharged on November 30th. A freshcomplexioned youth, who had been a bricklayer's labourer in London prior to enlistment. On admission he was found to have two well-marked rupial ulcers on his left forearm, over the site of a man's head tattooed by S. From the lower ulcer the chief part of the limpet-shaped scab had separated, but the upper one was intact. The bases were indurated, and margins of a dusky red (copper colour). Both the brachial, cervical, and inguinal glands were enlarged, and he had some lepra on his forehead at the junction of the hair, also a roseolar rash over the abdomen. He was tattooed on May 18th, 1888, and the ulcers appeared on June $12 \mathrm{th}$, an incubation of 26 days. He had never before had syphilis. Since admission, the second rupial scab fell off, leaving two plain copper-coloured scars. He had also impetigo of scalp and sore throat. He had been previously tattooed, but not by S., but no ulceration followed. Treatment : mercury, pot. iod., and tonics; result: recovery. He stated that $S$. did not use his saliva in any form or put the needles in his mouth, hence the paints must have been mixed with saliva.

CaSE VI.-Private H. S., aged 19; eervice 11 menths. Ad- 
mitted on October 15th, 1888, and discharged on November 30th. A fair-complexioned youth, who had been a weaver at Ashtonunder-Lyme prior to enlistment. On admission he was found to have two copper-coloured scars on the front of the right forearm, over the seat of tattooing of a female figure by S. There was slight induration round the margins of the scar. His cervical and inguinal glands were enlarged. He had a copper-coloured rash over both arms, at the bend of the elbow, and also on the scrotum, like psoriasis guttata; also condylomata ani. He was tattooed on June 1st, and the ulcers appeared on the 20th of the same month, an incubation of 20 days. He had never before had syphilis. Since admission he had sore throat, psoriasis, mucous tubercles, and alopecia. Treatment: mercury, pot. iod., and tonics; result: recovery. He stated that $S$. did not put his needles in his moutb, but rubbed the woind with his saliva.

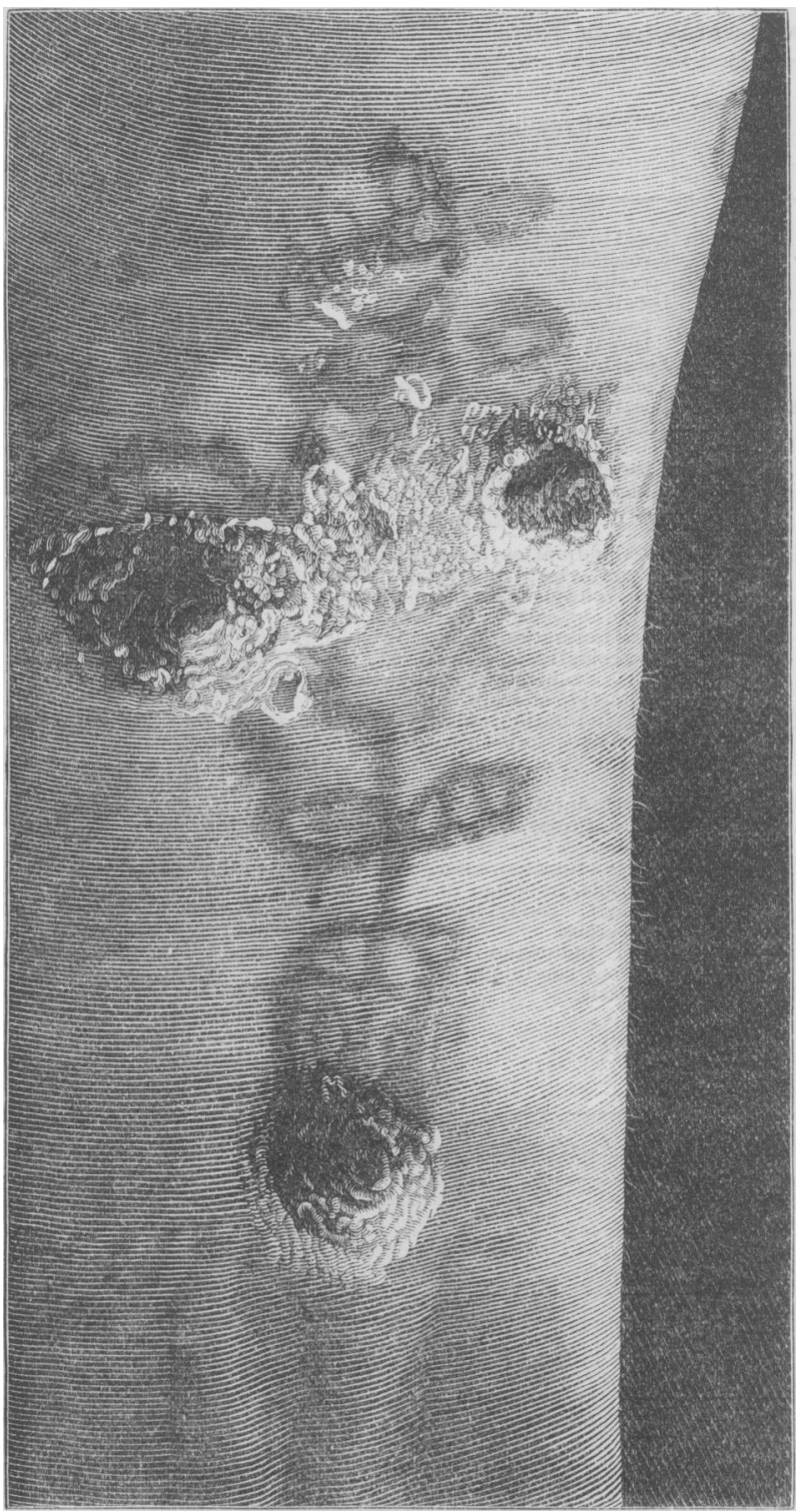

Fig. 3.-Case IV

CASE vir.-Private J. L. J., aged 18; service 8 months. Admitted on October 16th, 1888, and discharged on November 30th. A dark-complexioned youth, who was an ostler in London prior to enlistment. On admission he was found to have a coppercoloured scar of an ulcer, with slight induration, situated on the front of his left forearm, on the site of a female figure tattooed by S. He also had enlarged glands in the axilla, an 1 a coppery rash over the body (abdomen and back), in parts resembling psoriasis guttatta, in others roseola; also a rash on the scrotum and condylomata ani. He was tattooed on June 29 th, 1888, and the ulcers appeared on August 10tb, an incubation of 43 days. He had never had syphilis before. Since admission he had sore throat, numerous tubercles, and impetigo of sculp, with enlargement of inguinal glands. Treatment : mercury, pot. iod., and tonics; result: recovery. He had another figure (done from a pattern also) on his other arm, at the same time by S., but no ulceration followed. He stated that $S$. put the needles in his mouth, but did not use his saliva to wet the pattern or mix his paints.

CASE VIII.-Private J. B., aged 21 ; service 11 months. Admitted on October 16th, 1888, and discharged on November 30th. A dark-complexioned youth, who was a steam ploughman at Winchester prior to enlistment. On admission he was found to have four copper-coloured scars, from which limpet-shaped scabs had fallen off, leaving a plain surface with some induration round the margins, situated on the flexor surface of his left forearm, over the site of a heart, cross, and anchor tattooed (not from pattern) by $\mathrm{S}$. He had also enlarged brachial, cervical, and inguinal glands, and a roseolar rash and psoriasis guttatta, over the body, also on the scrotum, together with condylomata ani, also sore throat, with slight ulceration of fauces. He was tattooed on June 29 th, 1888, and the ulcers appeared on August 15th, an incubation of 48 days. He had never had syphilis before. Since admission ulceration of soft palate increased, and he had mucous tubercles. Treatment: mercury, pot. iod., and tonics ; result: recovery. $\mathrm{H}_{\Theta}$ had a figure (female) done from pattern on the other arm, at the same time by $S$., but no ulceration followed. He stated that he did not notice $S$. put the needles in his mouth, or use his saliva in any form.

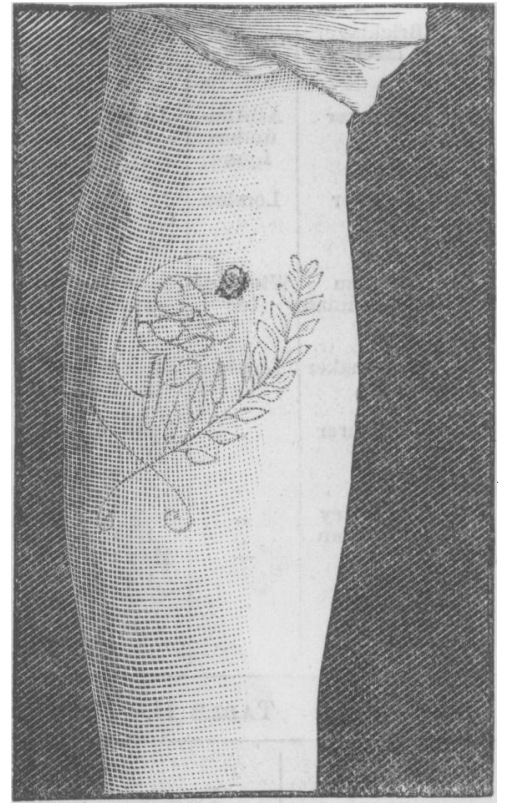

Fig. 4.-Case Ix.

CASE IX.-Lance-Corporal H. L., aged 21 ; service 1 year and 9 months. Admitted on October 17th, 1888, and discharged on November 11th. A fair-complexioned youth, who was a bootmaker in London prior to enlistment. He came to the hospital on October 9th, when he was found to have a small ulcer the size of a dried pea, with indurated base, but was not admitted till a week afterwards. On admission he was found to have an ulcer the size of a sixpence, with markedly indurated base, on the flexor surface of the left forearm, over the site of a rose tattooed by S., and his cervical glands were enlarged. He was tattooed on August 5th, 1888, and the ulcer appeared on October 2nd, an incubation of 59 days. He had never had syphilis before. Since admission his inguinal glands were found to be enlarged, and he had sore throat, psoriasis, and mucous tubercles. Treatment: mercury, pot. iod., and tonics; result: temporarily relieved. He was discharged from hospital to go to Malta to join his regiment, but has since been (January $24 \mathrm{th}, 1889$ ) readmitted with marked psoriasis, and sore 
throat and mucous tubercles. He stated that $\mathrm{S}$. mixed his colours with his "saliva:"

CaSE X.-Private G. J., aged 20; service 18 months. A freshcomplexioned youth, who was a labourer in London prior to enlistment. Admitted on October 19th, 1888, and discharged on November 30th. On admission he was found to have two scars of a purplish red colour, with slight induration at the margins, on the flexor surface of the right forearm, over the site of a female figure tattooed by $\mathbf{S}$. The scars had had rupiæ on them, and were not quite healed. He had also enlarged glands in the right axilla, commencing impetigo of scalp, a roseolar rash over the body, and ulceration of fauces. He was tattooed on June 15th, and the ulcers appeared on July 15th, an incubation of 31 days. He had never had syphilis before. Since admission the ulcers have broken down again, and secondary rupiæ formed, which afterwards healed. His inguinal and cervical glands were enlarged. The impetigo came and went. He had sore throat, mucous tubercles, and condylomata ani. Treatment: mercury, pot. iod., and tonics; result: relieved. He was discharged from hospital to join his regiment in Malta. He stated that $\mathbf{S}$. used his saliva to rub his right arm, on which a female figure was tattooed, but used a cloth to rub the left arm, on which he tattooed another female figure on the same date, but the latter did not ulcerate. He also stated that $\mathrm{S}$. used his saliva to apply the patterns with the figures on.

CASE Xr.-Private A. T. S., aged 20; service 10 months. A freshcomplexioned youth, who, prior to enlistment, was a dollyman in a laundry in London. He was inspected at the hospital on October 23rd, 1888, when he was found to have three copper-coloured scars on his left forearm, over the site of a female figure tattooed

TABLE I.-Cases in which Syphilis was contracted by Tattooing.

\begin{tabular}{|c|c|c|c|c|c|c|c|c|c|c|c|c|c|}
\hline $\begin{array}{l}0 \\
\vdots \\
⿱ 亠 乂 \\
\vdots \\
0 \\
0\end{array}$ & Name. & $\stackrel{\infty}{4}$ & 这 & $\begin{array}{c}\text { Former } \\
\text { Occupation. }\end{array}$ & 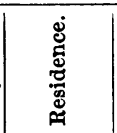 & 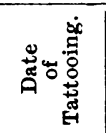 & 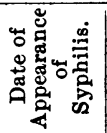 & 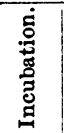 & 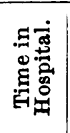 & | & $\begin{array}{l}\text { Nature } \\
\text { of } \\
\text { Sore. }\end{array}$ & Syphilitic Lesions. & Remarks. \\
\hline 1 & J. G. & 19 & $\operatorname{mins}_{12}$ & $\begin{array}{l}\text { Shipyard } \\
\text { labourer }\end{array}$ & Newc'stle & $\begin{array}{l}\text { July 1, } \\
1888\end{array}$ & $\begin{array}{l}\text { Sept. 25, } \\
1888\end{array}$ & days & $\begin{array}{c}\text { days } \\
57\end{array}$ & 2 & $\begin{array}{c}\text { Hunterian } \\
\text { chancre }\end{array}$ & $\begin{array}{l}\text { Local induration, enlarged glands, } \\
\text { roseolar rash, sore throat, im- }\end{array}$ & $\begin{array}{l}\text { Tattooed on other arm by S., } \\
\text { but no ulceration followed. }\end{array}$ \\
\hline 2 & A. $\mathrm{L}$ : & 20 & 24 & Zinc worker & London & $\underset{1888}{\text { Aug. 5, }}$ & $\underset{1888}{\text { Sept. }}$, & 29 & 66 & 2 & " & $\begin{array}{l}\text { Local induration, enlarged glands, } \\
\text { psoriasis, roseolar rash, sore } \\
\text { throat }\end{array}$ & $\begin{array}{l}\text { Secondary rupia formed at the } \\
\text { seat of ulceration after prim- } \\
\text { ary scabs fell off. }\end{array}$ \\
\hline 3 & G. R.S. & 19 & 9 & $\begin{array}{l}\text { Driver of } \\
\text { cart }\end{array}$ & ," & $\underset{1888}{\text { Aug. 5, }}$ & $\underset{1888}{\text { Sept. 20, }}$ & 47 & 55 & 1 & ", & $\begin{array}{l}\text { Local induration, enlarged glands, } \\
\text { roseolar rash, sore throat }\end{array}$ & \\
\hline 4 & A. $\mathrm{M}$. & 20 & 11 & $\begin{array}{c}\text { Pianoforte } \\
\text { maker }\end{array}$ & " & $\underset{1888}{\text { Aug. } 11}$ & $\underset{1888}{\text { Aug. } 23,}$ & 13 & 53 & 3 & Rupial ulcer & $\begin{array}{l}\text { Local induration, enlarged glands, } \\
\text { lepra, sore throat, condylomata }\end{array}$ & $\begin{array}{l}\text { Had previously been tattooed } \\
\text { but not by S., no ill effect } \\
\text { followed. }\end{array}$ \\
\hline 5 & J. T. & 19 & 10 & $\begin{array}{c}\text { Bricklayer's } \\
\text { labourer }\end{array}$ & ", & $\underset{1888}{\operatorname{May} 18}$ & $\underset{1888}{\text { June }} 12$ & 26 & 49 & 2 & $"$ & $\begin{array}{l}\text { Local induration, enlarged glands, } \\
\text { impetigo of scalp, sore throat, } \\
\text { roseolar rash }\end{array}$ & $\begin{array}{l}\text { Was tattooed by S. on opposite } \\
\text { arm, but no ulceration fol- } \\
\text { lowed though done at same } \\
\text { time. }\end{array}$ \\
\hline 6 & II. $\mathrm{S}$. & 19 & 11 & Weaver & $\begin{array}{l}\text { Ashton- } \\
\text { under- } \\
\text { Lyme }\end{array}$ & $\begin{array}{l}\text { June 1, } \\
\text { los8 }\end{array}$ & $\underset{1888}{\text { June } 20}$ & 20 & 47 & 2 & $\underset{\text { chancre }}{\text { Hunterian }}$ & $\begin{array}{l}\text { Local induration, enlarged glands, } \\
\text { roseolar rash, sore throat, psoria- } \\
\text { sis, condylomata, mucous tuber- }\end{array}$ & $\begin{array}{l}\text { time. } \\
\text { Stated s. rubbed the wound } \\
\text { with his saliva. }\end{array}$ \\
\hline$\pi$ & J. L. J. & 18 & 8 & Ostler & London & $\begin{array}{c}\text { June } 29, \\
1888\end{array}$ & $\underset{1888}{\text { Aug. } 18}$ & 43 & 46 & 1 & $\because$ & $\begin{array}{l}\text { cles, alopecia } \\
\text { cocal induration, enlarged glands, } \\
\text { roseolar rash, sore throat, mu- } \\
\text { cous tubercles, condylomata, } \\
\text { invetiog of scalp }\end{array}$ & $\begin{array}{l}\text { Stated S. put the needles in } \\
\text { his mouth; tattooed on other } \\
\text { arm by S., no ulceration fol- } \\
\text { lowed. }\end{array}$ \\
\hline 8 & J. B. & 21 & 11 & $\begin{array}{c}\text { Steam } \\
\text { ploughman }\end{array}$ & $\underset{\text { ter }}{\text { Winches- }}$ & $\begin{array}{l}\text { June } 29 \\
1888\end{array}$ & $\underset{1888}{\text { Aug. } 15,}$ & 48 & 46 & 4 & Rupial ulcer & $\begin{array}{l}\text { Local induration, enlarged glands, } \\
\text { psoriasis, sore throat, condylo- } \\
\text { mata }\end{array}$ & $\begin{array}{l}\text { Tattooed on other arm by } S \text {., } \\
\text { but no ulceration followed; } \\
\text { states S. did not put needles } \\
\text { in his mouth. }\end{array}$ \\
\hline 9 & H. L. & 21 & 21 & Bootmaker & London & $\underset{1888}{\text { Aug. } 5}$ & $\begin{array}{c}\text { Oct. 2, } \\
1888\end{array}$ & 59 & 45 & 1 & $\begin{array}{c}\text { Hunterian } \\
\text { chancre }\end{array}$ & $\begin{array}{l}\text { Local induration, enlarged glands, } \\
\text { sore throat, psoriasis, mucous } \\
\text { tubercles }\end{array}$ & $\begin{array}{l}\text { Stated S. mixed his colours } \\
\text { with his saliva. }\end{array}$ \\
\hline 10 & A.T.S. & 20 & 18 & Labourer & ," & $\underset{1888}{\text { June } 15}$ & $\begin{array}{l}\text { July 15, } \\
1888\end{array}$ & 41 & 42 & 2 & $\begin{array}{l}\text { Rupial ulcer } \\
\text { Hunterian }\end{array}$ & $\begin{array}{l}\text { Local induration, enlarged glands, } \\
\text { roseola, impetigo of scalp, sore } \\
\text { throat, condylomata, mucous } \\
\text { tubercles } \\
\text { Local induration, roseola, sore }\end{array}$ & $\begin{array}{l}\text { Tattooed on his left arm by } \mathrm{S} \text {. } \\
\text { at same time, to which } \mathrm{S} \text {. } \\
\text { used a cloth; no ulcer, but } \\
\text { rubbed right with saliva. } \\
\text { Tattooed before, no ill effect. }\end{array}$ \\
\hline 12 & W. H. T. & 20 & 14 & & - & $\begin{array}{l}1888 \\
\mathbf{1 8 8 8} 18\end{array}$ & & - & - & 2 & $\begin{array}{l}\text { chancre } \\
\text { Rupial ulcer }\end{array}$ & \begin{tabular}{|l} 
throat, condylomata \\
Psoriasis
\end{tabular} & $\begin{array}{l}\text { Sailed for India early in Octo- } \\
\text { ber, hence so few data ; states } \\
\text { S. was in habit of spitting on } \\
\text { arm during tattooing opera- } \\
\text { tion. }\end{array}$ \\
\hline
\end{tabular}

TABLE II.-Cases in which Syphilis was not contracted after Tattooing.

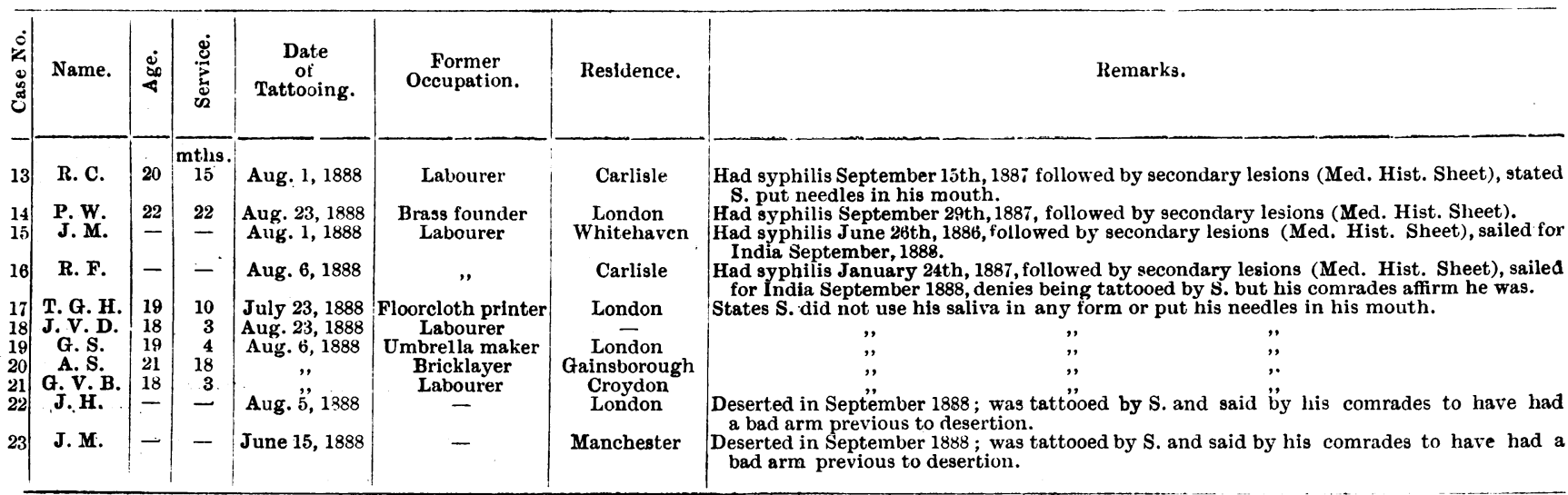


by $\mathrm{S}$. He had also a roseolar rash on the abdomen, cervical and inguinal glands enlarged, none in the axilla, slight ulceration of both tonsils, and condylomata. He was tattooed on June 15th, 1888 , and ulcers appeared on August 24th, an incubation of 41 days. He had never before had syphilis. The patient was not admitted to hospital, but permitted to accompany his regiment to Malta. He stated that $S$. neither put his needles in his mouth, nor used his saliva when tattooing.

CASE XII.-Private W. H. T., aged 20; service 14 months. He sailed for India to join the 1st battalion of his regiment at the end of September, 1888, prior to this inquiry. He was tattooed on May 18th, 1888, by S., on his right arm-a female figure. I am indebted to Surgeon-Major R. W. Davies, M.S., in medical charge of the station hospital at Sialkote for the following information of this case in answer to queries: $a$, ulceration had existed over the tattoo marks of the right arm; $b$, from his (the patient's) own description, and from present observation, the nature of the eruption was probably rupial; $c$, he never had syphilis before or after enlistment; $d$, there were spots of a suspicious nature on his chest.

The following are the chief points of interest in this outbreak of syphilis.

Age.-It occurred amongst young and healthy soldiers, whose ages ranged from 18 to 22 years, with a service of from 3 to 24 months.

Occupation.-Although many of them had lived in London, following occupations which were not in themselves injurious to health, and others were employed in the country, their general appearance was that of fresh-complexioned vigorous lads, who had lived healthy lives.

Incubation Period. - It is interesting to note the difference in the incubation periods in cases which were tattooed the same day as Cases II, III, and IX, which were 29,47 , and 59 days respectively. The incubation periods varied from 13 days, the shortest (Case IV) to 87, the longest (Case I). The length of incubation period appears to have had no effect in determining the severity of the secondary symptoms, or on the form of ulceration taken, Hunterian or rupial.

The Number of Points of Inoculation.-It is a fact worthy of notice, that when syphilis is contracted in the ordinary way, viâ penis by sexual intercourse, we rarely have more than one true Hunterian chancre, although at the same time we may have several soft sores or local ulcers, showing that there existed more than one abrasion, through which inoculation might have occurred, yet in one of these cases (No. vIII) we had four distinct rupial sores in an area of a circle of an inch and a half in diameter; also that the severity of the secondary phenomena was not proportional to the number of points of inoculation; Case IX, with only one ulcer, being the most intractable. It is curious to note that although Cases I, II, V, VII, VIII and $x$ were tattooed on both arms at the same time by $S$., in no instance did ulceration occur on more than one arm.

Nature of the Sore.-It is the most remarkbble feature of these cases that out of the twelve examined, five should have presented a distinct rupial form, namely, Cases IV, v, VIII, $x$ and XII, and that Case II should have had secondary rupiæ at the seat of the IIunterian chancres. In no case in which rupial ulcers formed was there a single sore, but their numbers ranged from two to four. In no case did rupiæ form in other parts of the body. I never before heard of rupiæ furming at the seat of the primary sore, and always thought they were regarded as tertiary manifestations; but here we have them as primary or early secondary. Finding in the article on Syphilis, by Mr. Jonathan Hutchinson, in the Dictionary of Practical Surgery, it stated that rupia never occurs very early amongst the secondary phenomena, its usual place being from six to twelve months after the chancre, I forwarded a copy of photo., being that of Case IV, to Mr. Hutchinson, who wrote, "I have repeatedly seen primary chancres, when occurring on the naked skin, assume more or less closely the features of rupiæ. You will see one of those figured in my clinical illustrations in connection with syphilis from vaccination, in which the sores had much this aspect. I may admit that I have never seen the simulation quite so clear as is figured in your photo." The rupiæ when seen were of the rupia prominens form, resembling limpet shells, and when they fell off left a plain, not an excavated base.

Syphilitic Lesions.-These were very uniform in all cases, occurring as enlarged glands, rash, sore throat, condylomata, and mucous tubercles, and usually in this order.
Inoculation: Source of Virus.-There can be no doubt that the man S. was the cause of the disease manifesting itself, and that his saliva was the source of the virus, for: (1) No man in any other regiment in the station, tattooed during the same period, contracted the disease, because they were not done by him. (2) Men in the same regiment tattooed, but not by $S .$, did not contract the disease. (3) S. owned he might have put the needles in his mouth Case VII stated that $\mathbf{S}$. did put the needles in his mouth. (4) Case IV stated that the needles before use were dirty, as if used before. (5) Case vI stated that $S$. rubbed the wound with saliva; S. himself afterwards owned that he might have rubbed the wounds with his saliva; Case $\times$ stated that $\mathbf{S}$. rubbed his left arm with a cloth; no ulceration followed; but that he rubbed his right with his saliva, and ulceration followed; Case XIr stated that $S$. was in the habit of spitting on the arm during the process. (6) Case $x$ also stated that $S$. had about twenty patterns on paper, mostly female figures, printed in copying ink, each pattern being able to be used about six times (Cases VI, VIII, XIII, XVII, XIX, and $\mathrm{xx}$ were found to be done with the same pattern); he said S. wetted the pattern with saliva before applying it, to obtain an impression. (7) Case IX stated he saw S. mix the colours, in a small cup he had, with his saliva.

Summary as to Immunity from second Attack-We find that out of the twenty-three cases known to have been tattooed by $S$, twelve cases contracted the disease, never having had syphilis previously; two cases are stated to have contracted syphilis, but, having deserted, all trace of them is lost ; four cases did not contract the disease, having previously had syphilis, showing the immunity one attack affords, although Case XIII stated S. had put the needles in his mouth; five cases did not contract the disease, although none of them had ever had syphilis, and each one denied that S. had put his needles in his mouth or used his saliva in any way.

\section{FIFTEEN MONTHS' EXPERIENCE OF ELECTRIC ILLUMINATION OF THE BLADDER, IN THE DIAGNOSIS OF OBSCURE VESICAL DISEASE. ${ }^{1}$}

BY E. HUR.RY FENWICK, F.R.C.S., Assistant-Surgeon to the London Hospital ; Surgeon (Out-Patient) to St. Peter's Hospital for Urinary Diseases.

I HAVE already ${ }^{2}$ urged the paramount necessity for unremitting practice with the electric cystoscope, if any degree of accuracy in diagnosis, prognosis, and treatment is aimed at, in order to enable the observer to avoid the many pitfalls or visual fallacies which the mucous membrane of the bladder presents both in health and disease under electric light.. It is perfectly true that a novice may recognise a typical growth or a glistening stone without difficulty, but it is also equally true that the inexperienced cystoscopist will be readily and more often deceived by the perplexing appearances which the mucous membrane is wont to assume under the varying conditions of relaxation, congestion, extravasation, and infiltration, and may be tempted to interfere operatively, to his own and the patient's detriment, under the belief that he has to deal with a growth, when no such morbid condition is present. I have already seen such a mistake happen twice, and 1 wish therefore to preface the real object of this communication, by drawing attention to certain conditions, which are most likely to prove deceptive. Visual fallacies in electric cystoscopy may be grouped under two headings : 1 . Those encountered in the healthy bladder. 2. Those met with in the diseased bladder.

1. The Healthy Bladder.

(a) The Ureteral Cone.-The first normal pitfall to be avoided is a slightly prolapsed ureter. The vesical orifice of the ureter usually appears as a pouting thick-lipped orifice, but even in perfect health it may be seen as a red gelatinous-looking cone, more

1 Abstract of a paper read before the Medical Society of London, on March 11th. The snbject was illustrated by patholngical specimens, wax and clay models of the living bladder, and photographs taken by means of the cystoscope.

2 Electrie Endoscopy, p. 48. 